\title{
Zakat Fitrah di Lembaga Pendidikan Perspektif Mazhab Syafi’i dan Mazhab Hanafi
}

\author{
Kiki Ayu Rohmawati \\ Fakultas Syariah UIN Maulana Malik Ibrahim Malang \\ qikqik_aiuk@yahoo.co.id
}

\begin{abstract}
:
Zakat is the third of pillars of Islam, which is very important for improving the existence of Muslim worship beside of prayer and fasting, so zakat fitrah is carried so much by Elementary Schools and Islamic Elementary Schools to be used as a basic learning by way of zakat payment practice in schools. There are two of education institutions carried by the author. They are Bandar II Elementary School and Ihsan al-Bandar Islamic Elementary School, Kedung Mulyo village, Bandar Kedung Mulyo sub-district, Jombang. In November 2014 ago.nThe main purpose of this study is to understand the practice of zakat fitrah applied in Elementary School and Islamic Elementary School in Bandar Kedung Mulyo Village, Bandar Kedung Mulyo sub-district, Jombang, and to review the law of Syafi'i and Hanafi sect perspective. In this study uses the type of empirical research with qualitative approach. Most of the primary data collected through semi-structured interviews and field observations. Literature and related documentation of this issue are used as the secondary data. After collecting the data, then analyze it by using qualitative descriptive method. Based on the analysis, the conclusion is zakat fitrah in Elementary School and Islamic Elementary School of Bandar Kedung Mulyo has different characteristics and practices in collecting zakat, zakat distribution, and the time of collection and dividing of zakat. The difference is because of Bandar II Elementary School tends to be proportional to follow the Syafi'i and Hanafi sect, whereas in al-Ihsan Islamic Elementary School tends to follow or taqlid at one sect, that is Syafi'i sect.
\end{abstract}

Zakat adalah rukun ketiga dari rukun Islam, yang sangat penting untuk meningkatkan keberadaan ibadah Muslim samping doa dan puasa, sehingga zakat fitrah dilakukan begitu banyak oleh Sekolah Dasar dan Sekolah Dasar Islam untuk digunakan sebagai pembelajaran dasar dengan cara praktek pembayaran zakat di sekolah. Ada dua lembaga pendidikan yang dilakukan oleh penulis. Mereka adalah Bandar II Sekolah Dasar dan Ihsan al-Bandar Sekolah Dasar Islam, Desa Kedung Mulyo, Bandar Kedung Mulyo Kecamatan, Jombang. Pada November 2014 ago.nThe Tujuan utama dari penelitian ini adalah untuk memahami praktek zakat fitrah diterapkan di Sekolah Dasar dan Madrasah Ibtidaiyah di Bandar Kedung Mulyo Desa, Bandar Kedung Mulyo Kecamatan, Jombang, dan untuk meninjau hukum Syafi'i dan perspektif Maadzhab Hanafi. Dalam penelitian ini menggunakan jenis penelitian empiris dengan pendekatan kualitatif. Sebagian besar data primer dikumpulkan melalui wawancara semi-terstruktur dan observasi lapangan. Sastra dan dokumentasi terkait masalah ini digunakan sebagai data sekunder. Setelah mengumpulkan data, kemudian menganalisisnya dengan menggunakan metode deskriptif kualitatif. Berdasarkan analisis, kesimpulannya adalah zakat fitrah di Sekolah Dasar dan Sekolah Dasar Islam Bandar Kedung Mulyo memiliki karakteristik yang berbeda dan praktek dalam mengumpulkan zakat, distribusi zakat, dan saat pengumpulan dan pembagian zakat. Perbedaannya adalah karena Bandar II Sekolah Dasar cenderung proporsional mengikuti 
Madzhab Syafi'i dan Hanafi, sedangkan di al-Ihsan Sekolah Dasar Islam cenderung mengikuti atau taqlid pada satu Madzhab, yang Madzhab Syafi'i.

Kata Kunci: zakat fitrah, lembaga pendidikan, madzhab

\section{Pendahuluan}

Islam adalah agama yang sempurna, dari berbagai seginya telah menuntun umat manusia untuk selalu memberikan kontribusi yang berguna bagi manusia yang lain di setiap sendi kehidupan. Kontribusi yang diberikan dengan maksud memberikan yang terbaik bagi diri sendiri maupun orang sekitar.Dari kontribusi-kontribusi terbaik tersebut tercipta keindahan dalam kehidupan berupa kepedulian sosial, tenggang rasa yang tinggi, dan rasa saling menyayangi diantara sesama manusia disetiap tempat dan zaman.Salah satu ajaran Islam yang memberikan bentuk kepedulian yang tinggi terhadap sesama manusia adalah zakat. Menunaikan zakat merupakan rukun Islam yang ketiga. Secara bahasa, zakat berarti tumbuh "numuww" dan bertambah "ziyâdah". Jika diucapkan zakat al-zar", artinya adalah tanaman itu tumbuh dan bertambah. Jika diucapkan zakat al-nafaqah, artinya nafkah tumbuh dan bertambah jika diberkati.Kata ini juga sering dikemukakan untuk makna thahârah (suci). ${ }^{1}$

Zakat dibagi menjadi dua, yaitu zakat fitrah dan zakat mal, zakat fitrah adalah zakat yang dikeluarkan pada saat puasa ramadhan diwajibkan untuk menyucikan diri, seorang yang berpuasa dari ucapan kotor dan perbuatan yang tidak ada gunanya. Zakat fitrah itu diberikan kepada orang-orang miskin untuk memenuhi kebutuhan mereka dan jangan sampai memintaminta pada hari raya itu. Sedangkan zakat mal adalah zakat yang bertujuan untuk membersihkan harta dari percampuran yang kurang halal.Pada dasarnya, zakat fitrah merupakan kontribusi wajib yang diajarkan oleh agama Islam untuk saling tolong menolong diantara umat Islam. Kewajiban membayar zakat fitrah dijelaskan dalam hadis yang Imam Syafi'i berkata : Dari Nafi', dari Ibnu Umar bahwasanya:

"Sesungguhnya Rasulullah SAW. Telah mewajibkan zakat fitrah pada bulan Ramadhan satu sha" kurma atau satu sha" gandum kepada setiap orang yang merdeka, hamba sahaya, baik laki-laki maupun perempuan dari kaum muslimin." (HR. Jama"ah Ahli Hadist $)^{2}$

Dari hadist diatas Rasulullah SAW, mewajibkan membayar zakat fitrah kepada setiap muslim, baik dalam bentuk satu sha" kurma ataupun satu sha" gandum. Baik laki-laki maupun perempuan muslimin. Oleh sebab itu, zakat fitrah menjadi sangat urgen yang harus diterapkan sejak dini karena menyangkut rukun dalam Islam yang harus terpenuhi. Zakat fitrah merupakan zakat wajib yang harus dikeluarkan oleh umat Islam, hukum zakat fitrah adalah wajib. Untuk menghilangkan was-was, ragu, sangka dan waham yang mungkin ditimbulkan oleh perselisihan ulama dalam soal ini, terdapat firman Allah Swt berfirman

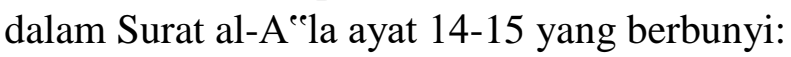

"Sungguh telah menang orang yang mengeluarkan zakat (fitrahnya) menyebut nama Tuhanmu (mengucap takbir, membesarkan Allah) lalu ia mengerjakan sembahyang (hari raya idul fitri)" (S. $87:$ Al A "la :14-15). ${ }^{3}$

Ayat Allah ini, menurut riwayat ibn Khuzaimah diturunkan berkenaan dengan zakat fitrah, takbir hari raya puasa dan shalat ,ied. Diambil pengertian dari ayat ini, bahwa zakat

\footnotetext{
${ }^{1}$ Wahbah Al-Zuhayly, Zakat Kajian Berbagai Madzhab, (Bandung: PT. Remaja Rosdakarya, 2005), 82

${ }^{2}$ Isa al-Baqi al-Halabi, al-Muwaththa', (Kairo:Ihya al-Kutub al-Arabiyah), Hadist No. 1479.

${ }^{3}$ Al-Quran, QS. Al- A'la, ayat 14-15, (Jakarta: CV Penerbit J-ART, 2005), 591.
}

Jurisdictie: Jurnal Hukum dan Syariah Vol. 6 No. 2 Desember 2015 
fitrah itu satu seluruh agama, satu pekerjaan yang mendatangkan keuntungan dan kemenangan. Namun adapun ulama yang menyatakan bahwa zakat fitrah tidak wajib bagi yang tidak berpuasa, diantara umat tersebut adalah al-Hasan al-Bishri, al-Sya "eby, Hal tersebut lantaran hikmahnya untuk mensucikan orang yang berpuasa. Namun pendapat tersebut dibantahkan oleh adanya hadist yang dikemukakan diatas bahwa menegaskan kefardluan zakat tersebut dengan tidak memandang kepada hikmah itu. Hanya saja dapat juga menjadi peringatan bagi setengah umat Islam yang lebih mementingkan fitrah daripada puasa. Puasa, mereka mudah-mudahkan, mereka abai-abaikan namun untuk fithrah mereka mau menggadaikan kain bajunya lantaran merasa malu tidak berfitrah. Sehingga seharusnya umat Islam selain mementingkan fitrahnya saja juga melaksanakan puasa. ${ }^{4}$

Eksistensi zakat fitrah di lembaga pendidikan bukanlah suatu hal yang baru, karena sudah sejak lama praktik zakat fitrah diadakan di lembaga pendidikan. Hal ini guna mengajarkan pada para siswa untuk menunaikan kewajiban membayar zakat fitrah yang biasanya diadakan pada akhir bulan Ramadhan. Keberadaan zakat fitrah di lembaga pendidikan sudah tidak asing lagi, terutama di lembaga pendidikan Islam, seperti Madrasah Ibtidaiyah, Madrasah Tsanawiyah dan Madrasah Aliyah. Dan meskipun demikian eksistensi zakat fitrah tidak hanya ada di lembaga pendidikan Islam saja akan tetapi juga Sekolah Umum yaitu Sekolah Dasar (SD), Sekolah Menengah Pertama (SMP), dan Sekolah Menengah Atas (SMA) yang juga mengimplementasikan zakat fitrah setiap bulan Ramadhan.

Salah satu lembaga Pendidikan Islam yang menerapkan implementasi zakat fitrah adalah MI al-Ihsan, sedangkan lembaga pendidikan umumnya adalah SDN Bandar II. Penulis mengambil dua sampel sekolah tersebut, karena sekolah tersebut paling maju diantara yang lainnya, dan layak mewakili penelitian ini. Implementasi zakat fitrah antara lembaga pendidikan Islam dan lembaga pendidikan umum seperti halnya MI al-Ihsan dan SDN Bandar II seperti yang disebutkan di paragraf sebelumnya tidak terlepas dari perbedaan, yaitu diantaranya adalah perbedaan waktu pengumpulan zakat, perbedaan ukuran dan jenis benda yang digunakan untuk membayar zakat fitrah, perbedaan siapa-siapa yang disebut muzakki juga mustahiq, dan lain sebagainya. Perbedaan tersebut ada karena beberapa faktor dan salah satu faktornya adalah mazhab yang dipakai oleh masing-masing lembaga pendidikan, baik SekolahIslam maupun Sekolah umum.

Perbedaan tersebut perlu adanya penulisan untuk mendiskripsikan praktik zakat fitrah antara satu lembaga pendidikan dengan lembaga pendidikan lain, karena perbedaan tersebut telah menuai banyak tanda tanya dari beberapa kalangan terutama kalangan masyarakat awam yang mendapati perbedaan praktik secara umum zakat fitrah antara satu sekolah dengan sekolah yang lain. Adanya protes dari kalangan masyarakat awam didasari karena kurangnya pengetahuan tentang zakat fitrah sendiri serta dimungkinkan karena kurangnya sosialisasi dari pihak sekolah maupun tokoh agama setempat. Latar belakang masalah yang telah disampaikan di muka merupakan gambaran nyata tentang masalah yang sedang terjadi di tengah masyarakat dan jarang dipahami oleh para akademisi sehingga penulis ingin mengupas lebih dalam terhadap teori mengenai praktik zakat fitrah yang ada di Sekolah Dasar dan Madrasah Ibtidaiyah yang ada di Desa Bandar Kedung Mulyo, dengan membandingkannya dengan teori yang disampaikan oleh mazhab Syafieci dan mazhab Hanafi. Tujuan penulisan artikel ini adalah untuk mengetahui praktik zakat fitrah di lembaga pendidikan Sekolah Dasar dan Madrasah Ibtidaiyah di Desa Bandar Kedung Mulyo Kecamatan Bandar Kedung Mulyo Kabupaten Jombang. Untuk mengetahui perspektif mazhab Syafieci dan mazhab terhadap

\footnotetext{
${ }^{4}$ Teuku Muhammad Hasbi, Pedoman Zakat,(Semarang: PT. Pustaka Rizki Putra, 1999), 251.
}

Jurisdictie: Jurnal Hukum dan Syariah Vol. 6 No. 2 Desember 2015 
implementasi zakat fitrah di lembaga pendidikan Sekolah Dasar dan Madrasah Ibtidaiyah di Desa Bandar Kedung Mulyo Kecamatan Bandar Kedung Mulyo Kabupaten Jombang.

\section{Metode Penelitian}

Penelitian ini termasuk dalam katagori penelitian hukum empiris yang bersifat deskriptif. Pendekatan yang digunakan dalam penelitian ini adalah pendekatan kualitatif. Penelitian ini mengambil lokus di Sekolah Dasar Bandar Dua dan Madrasah Ibtidaiyah AlIhsan Desa Bandar Kedung Mulyo Kecamatan Bandar Kedung Mulyo Kabupaten Jombang. Sumber data primer berupa hasil wawancara semi terstuktur terhadap Kepala Sekolah SDN Bandar Dua dan Madrasah Ibtidaiyah al-Ihsan serta siswa yang menempati kelas atas. Sumber data sekunder yang akan digunakan dalam penulisan ini meliputi: Zakat Kajian Berbagai Madzhab karya Wahbah az-Zuhaily; Fiqh az-Zakat karya Yusuf Qardhawi, Fiqih Sunnah karya Sayid Sabiq, Fiqh dan Manajemen Zakat di Indonesia karya Fakhruddin, Fiqih Islam wa Adillatuhu karya Wahbah az-Zuhaily; Zakat dan Infak karya M. Ali Hasan; Zakat Perekonomian Modern karya Didin Hafidhuddin.

\section{Hasil dan Pembahasan}

\section{Zakat Fitrah di Lembaga Pendidikan Perspektif Imam Mazhab}

Untuk mendapat gambaran dan analisis terhadap zakat fitrah di Lembaga Pendidikan khususnya di SDN Bandar II dan MI al-Ihsan, maka masing-masing akan dipaparkan secara tematik dan sistematis. Zakat Fitrah merupakan rukun Islam yang wajib bagi atas setiap muslim untuk membayarnya, seiring dengan perkembangan zaman keberadaan zakat fitrah dikhawatirkan dapat lekang oleh waktu, oleh sebab itu eksistensinya tetap dijaga oleh para pejuang muslim, yang diantaranta adalah para guru, yang tetap menerapkan praktik zakat fitrah di Lembaga Pendidikan. Zakat Fitrah menurut Sayyid Sabiq mengartikan zakat fitrah sebagai zakat yang wajib dilaksanakan sebab selesainya puasa Ramadhan, hukum wajib ini berlaku bagi setiap muslim, baik kecil atau dewasa, laki-laki atau perempuan, merdeka atau budak belian. ${ }^{5}$

Menurut Wahbah az-Zuhaili, zakat fitrah adalah zakat wajib yang dikeluarkan sebagai alat penyuci jiwa, karena manusia adalah mahkluk yang barang kali kotor. ${ }^{6}$ Berdasarkan praktiknya, di SDN Bandar II dan MI al-Ihsan yang merupakan contoh dari lembaga pendidikan yang menerapkan praktik zakat fitrah berbeda satu sama lain dalam hal penunjukkan amil, penentuan mustahiq, penyaluran zakat, serta ukuran dan jenis benda yang dibayarkan zakat fitrah. Nur Ahmad, Selaku Kepala SDN Bandar II desa Bandar Kedung Mulyo beserta Ahmad Afandi selaku Guru Agama SDN Bandar II, Kecamatan Bandar Kedung Mulyo, Kabupaten Jombang,menuturkan :

"Keberadaan zakat fitrah di SDN Bandar II sudah ada sejak dari awal berdirinya, yaitu sejak tahun 1972, dan sejak adanya guru agama. Karena praktik zakat fitrah di SDN Bandar II tidak terlepas dari peran besar guru Agama. Bagaimana juga SDN Bandar II itu bukan sekolah Islam yang menuntut seluruh pengajar memahami agama Islam, oleh karena itu sekolah ini sangat

\footnotetext{
${ }^{5}$ Sayyid Sabiq, Fiqih Sunnah, jilid 3, (Bandung: PT. Al Maeearif, 1985), 348.

${ }^{6}$ Wahbah Zuhaili, Fiqih Islam wa Adillatuhu 3, terj. Abdul Hayyin al-Kattani, (Cet.III, Jakarta: Gema Insani, 2013), 167.
}

Jurisdictie: Jurnal Hukum dan Syariah Vol. 6 No. 2 Desember 2015 
mengandalkan guru agama sebagai kordinator dalam memimpin pelaksanaan zakat fitrah di SDN Bandar II", .

Sehingga dapat dinyatakan bahwa pelaksanaan zakat fitrah di SDN Bandar II adalah semenjak Sekolah mulai berdiri, yaitu tahun 1972. Dimana sejarah sekolah tidak diketahui dengan pasti oleh Nur Ahmad selaku Kepala Sekolah, karena pergantian Kepala Sekolah dari periode ke periode. Nur Ahmad juga menyatakan bahwa SDN Bandar II dalam hal pelaksanaan zakat fitrah sangat tergantung dengan keberadaan guru Agama, dengan dalih bahwa SDN Bandar II bukan Sekolah islam yang mewajibkan pengajarnya untuk memahami ilmu agama termasuk zakat fitrah. Tidak jauh berbeda awal praktik zakat fitrah di MI alIhsan, berdasarkan penuturan Siti Ghozilatul Fitriyah selaku Kepala MI al-Ihsan diantaranta adalah:

"Zakat fitrah di MI al-Ihsan sudah ada sejak Mi al-Ihsan berdiri, yaitu sejak tahun 1961. MI al-Ihsan berdiri dibawah naungan Pondok Pesantren salaf alIhsan, para pengajar diambil dari orang-orang yang mumpuni ilmu agama dan ilmu umum, sehingga meskipun mengajar matematika, bahasa Indonesia atau IPA, semua diharuskan muslim, memakai jilbab, dan minimal bisa mengaji" ${ }^{8}$

Berdasarkan penuturan dari Siti Ghozilatul Fitriyah, bahwa MI al-Ihsan tidak jauh berbeda dengan SDN Bandar II awal mula praktik zakat fitrah yaitu sejak berdirinya Madrasah tahun 1961, zakat fitrah dianggap sangat urgen sehingga setiap bulan Ramadhan selalu dilaksanakan. MI al-Ihsan merupakan Madrasah yang cukup selektif dalam pemilihan pengajar, karena selain mengajar ilmu umum guru minimal diwajibkan mengenakan jilbab dan dapat mengaji. Berbeda dengan SDN Bandar II yang tidak terlalu mementingkan kualitas ilmu agama bagi para pengajarnya. Hal ini wajar karena SDN Bandar II merupakan sekolah umum, yang pengajarnya tidak harus mengenakan jilbab, atau mengharuskan beragama Islam, sedangkan MI al-Ihsan merupakan cikal bakal dari Pesantren al-Ihsan yang sudah dapat dipastikan bahwa ilmu agama akan selalu melengkapi ilmu yang lain di Sekolah.

\section{Implementasi Zakat Fitrah}

Uraian mengenai implementasi zakat fitrah tergambar dari penjelasan yang diberikan Nur Ahmad selaku Kepala SDN Bandar II beserta Ahmad Affandi selaku Guru Agama SDN Bandar II dan Siti Ghozilatul Fitriyah selaku Kepala MI al-Ihsan, sebagai berikut :

"SDN Bandar II hanya mewajibkan zakat fitrah bagi mereka yang mampu saja, akan tetapi guna tidak ada perbedaan diantara para siswa semua mendapat pemberitahuan yang sama untuk wajib membayar zakat fitrah, pemberitahuan akan pembayaran zakat fitrah di SDN Bandar II dilaksanakan oleh pihak Sekolah pada awal bulan Ramadhan, dan untuk pembayaran zakat fitrah dilaksanakan di pertengahan bulan Ramadhan."9

Menurut Nur Ahmad, zakat fitrah di SDN Bandar II diwajibkan kepada siswanya yang mampu saja, akan tetapi untuk tidak membedakan antara si miskin dan si kaya, Nur Ahmad memberikan kebijakan bahwa untuk pemberitahuan semua diwajibkan membayar zakat. Sedangkan pembayaran zakat fitrah dilaksanakan di pertengahan bulan Ramadhan. Kemudian dari MI al-Ihsan, menyatakan mengenai implementasi zakat fitrah di MI al-Ihsan sebagai berikut:

\footnotetext{
${ }^{7}$ Nur Ahmad, Wawancara (Jombang, 22 November 2014)

${ }^{8}$ Siti Ghozilatul Fitriyah, Wawancara, (Jombang, 22 November 2014)

${ }^{9}$ Nur ahmad, wawancara (Jombang, 22 November 2014)

Jurisdictie: Jurnal Hukum dan Syariah Vol. 6 No. 2 Desember 2015
} 
"Pengumpulan zakat fitrah di Mi al-Ihsan, dilaksanakan di awal bulan ramadahan, sejak diberikan edaran pada awal Ramadhan siswa sudah mulai membayar zakat, dan bagi para siswa yang tidak mampu mendatangi guru mereka untuk menyampaikannya, sehingga tidak perlu membayar zakat dan mendapat zakat."

Berbeda waktu pengumpulan zakat antara SDN Bandar II dan juga MI al-Ihsan, namun keduanya masih dalam bulan yang sama yaitu bulan Ramadhan. MI al-Ihsan memilih waktu awal bulan Ramadhan untuk pengumpulan zakat fitrah, agar segera diserahkan kepada mustahiq. Perspektif mazhab Syafi'i adalah zakat fitrah dapat dikeluarkan pada hari pertama bulan Ramadhan. Tetapi lebih baik jika zakat fitrah dikeluarkan pada dua hari terakhir Ramadhan.Namun, pada sisi lain, waktu terbaiknya ialah pada hari pertama Idul Fitri sebelum Shalat 'Id, selebihnya maka dianggap sebagai sedekah biasa, Kata sebagain pengikutnya boleh diberikan zakat fitrah sejak tanggal 16 Ramadhan. ${ }^{10}$ Menurut Abu Hanifah boleh diberikan zakat fitrah itu sejak dari awal tahun. Akan tetapi secara teknis hal ini akan menyulitkan terutama bagi para petugas pengumpul zakat fitrah, karena itu para ulama berpendapat boleh saja dikeluarkan sepuluh hari atau seminggu sebelum hari Raya Idul Fitri. ${ }^{11}$

Maka perselisihan tersebut dapat terjawab dengan adanya hadist dari Abu Muhammad al-Maqdisi, isnadnya hasan dari Bulughul Maram sebagai berikut.

"Barang siapa mengeluarkannya (fithrah) sebelum bersembahyang hari raya, maka itulah zakat yang diterima, dan barang siapa mengeluarkannya sesudah sembahyang hari raya, maka pengeluarannya itu dipandang satu sedekah saja. (HR. Abu Daud dan Ibnu Majah)."

Dengan hadist ini terang dan nyata, bahwa masa kita diwajibkan mengeluarkan zakat fitrah itu ialah pagi hari raya dari terbit fajar hingga pergi ketempat sembahyang hari raya. Terkait dengan implementasi zakat fitrah di lembaga Pendidikan baik di SDN Bandar II dan juga MI al-Ihsan, dapat dinyatakan bahwa SDN Bandar II melaksanakan praktik zakat fitrah berdasarkan perspektif mazhab Syafi ${ }^{\text {ec }}$ juga Hanafi, karena mazhab Syafie $i$ memperbolehkan membayar zakat fitrah dengan ketentuan di akhir bulan Ramadhan sampai sebelum shalat Idul Fitri, sedangkan mazhab Hanafi memperbolehkan membayar zakat fitri sejak awal tahun dengan arti, zakat fitrah boleh dibayarkan kapanpun meskipun bulan Ramadhan.

Sedangkan MI al-Ihsan, lebih pada kepraktisan dalam membayar zakat fitrah dengan membayarkan zakat fitrah di awal bulan Ramadhan, hal ini menurut mazhab Syafieci maupun Hanafi juga diperbolehkan, akan tetapi jika zakat fitri difungsikan sebagai sedekah di hari raya untuk membantu orang-orang miskin agar tidak kelaparan di hari raya dan dapat merasa gembira, maka jarak awal bulan Ramadhan dan hari raya Idul Fitri menurut hemat Penulis adalah terlalu jauh sehingga zakat fitrah tidak sesuai sasaran karena dapat digunakan sebelum hari raya.

Terkait dengan muzakki dan Mustahiq zakat fitrah, Ahmad Afandi selaku guru Agama SDN Bandar II menyatakan bahwa:

"Delapan golongan yang disebutkan dalam al-Quran, amil zakat fitrah di Sekolah menentukan mustahiq diprioritaskan dari kalangan siswa yang kurang maтри atau miskin, kemudian selanjutnya diberikan kepada para siswa yang yatim, piatu atau yatim piatu. Selain itu amil zakat fitrah juga memberikan sebagian zakat fitrah pada masyarakat sekitar Sekolah dengan tujuan menjalin

${ }^{10}$ Yasin Ibrahim al-Syaikh, Zakat membersihkan Kekayaan, 102

${ }^{11}$ Didin Hafidhuddin, Panduan Zakat, (Jakarta: Republika, 2002), 120.

Jurisdictie: Jurnal Hukum dan Syariah Vol. 6 No. 2 Desember 2015 


\section{hubungan yang baik dengan masyarakat dan membantu masyarakat yang kurang maтри." 12}

Berdasarkan Data dan hasil wawancara dengan Nur Ahmad selaku Kepala SDN Bandar II, SDN Bandar II memprioritaskan bagi para siswa yang tidak mampu atau tergolong miskin, kemudian memberikan bagi para anak yatim, piatu, juga yatim piatu, selain itu amil juga mendapat bagian, yang disini sebagai amil adalah ketua Amil yaitu Ahmad Afandi dan para pengajar yang bertugas, selain itu sekolah juga membagikan pada warga sekitar sekolah yang dirasa tidak mampu dan berhak mendapatkan zakat. Kemudian di MI al-Ihsan, Siti Ghozilatul Fitriyah memaparkan menganai muzakki dan mustahiq adalah sebagai berikut:

\section{"sebagai mustahiq adalah dari kalangan siswa maupun masyarakat miskin.Hanya saja secara teknis MI al-Ihsan lebih sederhana pelaksanaannya karena minimnya tenaga pengajar juga para siswa." 13}

Mustahiq yang dikategorikan miskin oleh SDN Bandar II adalah dimana menurut perspektif mazhab Syafie $i$ adalah orang miskin keadaannya lebih baik daripada orang fakir, sedangkan menurut mazhab Hanafi orang miskin keadaannya lebih buruk daripada orang fakir, sehingga orang miskin lebih membutuhkan daripada orang fakir. ${ }^{14}$ Kemudian untuk muzakki, di SDN Bandar II seperti yang dijelaskan pada paparan data dimuka, bahwa SDN Bandar II mewajibkan seluruh siswanya membayar zakat fitrah namun apabila ada yang tidak mampu untuk membayar segera menghubungi guru agama atau guru yang bertugas sebagai amil zakat fitrah, dengan begitu siswa tidak lagi wajib membayar zakat fitrah. Kriteria muzakki berdasarkan perspektif mazhab Syafie $i$ adalah adalah yang Islam, merdeka, kondisi harta juga mencapai satu nisab lebih dari kebutuhan pokoknya, akan tetapi berbeda dalam hal baligh dan akal karena syarat baligh dan akal hanya dari ulama Hanafiyah saja, dan tidak untuk Syafieiyyah. Menurut Hanafiyah, orang yang wajib mengeluarkan zakat fitrah adalah setiap orang muslim yang merdeka, Islam, Baligh dan akal (tidak gila), kondisi harta mencapai satu nisab yang lebih dari kebutuhan pokoknya. ${ }^{15}$

Jadi kategori miskin yang dinyatakan kepala SDN Bandar II adalah kategori yang didasarkan pada pendapat mazhab Syafiei, karena menurut pernyataan Pak Nur Ahmad yang diprioritaskan sebagai mustahiq zakat fitrah adalah dari kalangan miskin bukan fakir, karena fakir menurut penatarannya lebih buruk disbanding miskin, sedangkan untuk kategori miskin sudah jarang ditemui, karena mayoritas, orang tua siswa memiliki pekerjaan baik tetap maupun tidak tetap. Sedangkan berdasarkan paparan teori di paragraf sebelumnya, bahwa yang dinyatakan sebagai muzakki dalam SDN Bandar II adalah seluruh siswa mulai dari kelas satu hingga kelas enam, sehingga lebih mengarah pada pendapat mazhab Syafie $i$, karena menurut mazhab Hanafi baligh termasuk syarat membayar zakat fitrah.

Dari penjelasan mengenai menentukan golongan mustahiq maka sama halnya dengan SDN Bandar II, MI al-Ihsan lebih cenderung kepada perspektif mazhab Syafie $i$, dimana yang dinyatakan miskin adalah adalah orang-orang yang mampu bekerja untuk menutupi kebutuhannya namun belum mencukupi, seperti orang yang membutuhkan sepuluh dia hanya mempunyai delapan sehingga tidak mencukupi sandang, pangan, papan. ${ }^{16}$ Berikut pemaparan

\footnotetext{
${ }^{12}$ Ahmad Afandi, wawancara, (Jombang, 22 November 2014).

${ }^{13}$ Siti Ghozilatul Fitriyah, wawancara, (Jombang, 22 November 2014)

${ }^{14}$ Jalaluddin Al-Mahalliy dan Imam Jalaluddin As-Suyuthi, Terjemah Tafsir Jalalain berikut Asbaabun Nuzul, 786.

${ }^{15}$ Wahbah az-Zuhaili, Fiqh Islam wa Adillatuhu 3, 175.

${ }^{16}$ Wahbah az-Zuhaili, al-Fiqhul Islam, 282.
}

Jurisdictie: Jurnal Hukum dan Syariah Vol. 6 No. 2 Desember 2015 
dari Ahmad Affandi mengenai ukuran dan jenis barang zakat fitrah yang ada di SDN Bandar II:

\begin{abstract}
"Ukuran yang dikenakan bagi para siswa dalam mengeluarkan zakat fitrah adalah 2,5 kg, namun pihak amil zakat fitrah menghimbau bagi para siswa untuk melebihkan zakat fitrah yang dikeluarkan, agar menghindari kurangnya nishab zakat fitrah. Bagi yang membayar dengan uang, seperti yang dijelaskan dimuka bahwa ukuran atau nishab zakat fitrah yang dikeluarkan sesuai dengan harga beras yang ditentukan oleh pihak amil zakat fitrah, jumlah tersebut relatif, karena pihak SDN Bandar II tidak menyebutkan nominalnya.Jadi disesuaikan dengan harga beras yang standart yaitu tidak terlalu murah juga tidak terlalu mahal."17
\end{abstract}

Imam Syafieci menyatakan biji gandum tidak dikeluarkan zakatnya kecuali satu shae saja, menurut sunnah Rasulullah SAW, zakat fitrah adalah berupa makanan pokok atau makanan yang biasa dimakan oleh seseorang. Makanan yang harus dikeluarkan sebagai zakat fitrah adalah makanan yang paling sering dimakan seseorang. Syafiei iyyah berpendapat bahwa zakat fitrah diambil dari mayoritas makanan pokok suatu negeri atau tempat dalam setahun. Bila ditemukan beberapa makanan pokok dalam satu negeri, maka yang diambil adalah yang terbaik kualitasnya. ${ }^{18}$ Hanafiyah berkata zakat fitrah wajib dikeluarkan dari empat benda, yaitu: gandum, beras, kurma, dan anggur. Mereka membolehkan memberikan zakat fitrah tersebut dengan harganya seperti dinar, dirham, uang, barang atau apa saja yang dia kehendaki karena hakikatnya yang wajib adalah mencukupkan orang fakir dan miskin dari meminta-minta. Boleh zakat fitrah dibayar dengan uang, demikian pendapat at-Tsauri, Abu Hanifah, Umar bin Abd. Aziz, dan Imam Hasan Basri. Abu Ishaq. ${ }^{19}$

Berdasarkan hasil penulisan, penulis mendapati praktik zakat fitrah di SDN Bandar II cenderung menggunakan pendapat mazhab Hanafi, dimana membolehkan membayar dengan menggunakan uang, selain itu jumlah uang yang ditentukan pihak amil zakat fitrah juga relatif, untuk mendapatkan beras dengan kualitas standart tidak terlalu baik juga tidak terlalu buruk, sehingga berbeda dengan mazhab Hanafi yang mewajibkan membayar zakat fitrah dengan kualitas yang terbaik. MI al-Ihsan juga tidak jauh berbeda dalam menentukan ukuran zakat fitrah yang harus dikeluarkan oleh para siswa, Siti ghozilatul Fitriyah memaparkan bahwa:

\title{
"Siswa membayar yaitu 2,5 kg. dan tidak mewajibkan siswanya untuk membayar zakat fitrah dengan kualitas yang terbaik. Hanya saja berbeda dengan SDN Bandar II, MI al-Ihsan tidak memperkenankan membayar dengan uang, hanya dengan bahan makanan pokok yang biasa dimakan oleh masyarakat setempat, yaitu beras." 20
}

Sehingga berdasarkan hasil penulisan di MI al-Ihsan, ukuran dan jenis zakat fitrah yang dikeluarkan adalah sebagaimana yang disebutkan oleh Imam Syafiec $i$ yaitu satu sha'. Sedangkan jenis zakat fitrah yang dikeluarkan juga sebagaimana perspektif mazhab Syafie $i$ dengan tidak memperkenankan membayar dengan uang. Karena pendapat Kepala MI al-Ihsan, membayar dengan uang tidak diperkenankan sudah sejak lama, mengingat bahwa MI

\footnotetext{
${ }^{17}$ Ahmad Afandi, hasil wawancara (22 November 2014)

${ }^{18}$ Imam Syafie $i$ Ringkasan al-Umm, 493.

${ }^{19}$ Didin Hafidhdin ,Panduan Zakat, 120-121.

20 Siti Ghozilatul Fitriyah, hasil wawancara, (di MI al-Ihsan, 22 November 2014)

Jurisdictie: Jurnal Hukum dan Syariah Vol. 6 No. 2 Desember 2015
} 
al-Ihsan banyak menganut mazhab Syafiei dalam kegiatan di Sekolah, baik teori maupun praktik, termasuk praktik zakat fitrah.

\section{Kesimpulan}

Berdasarkan pembahasan di atas dapat diambil kesimpulan: Pertama, SDN Bandar II menyalurkan zakat fitrah pada siswa yang kurang mampu, juga pada masyarakat sekitar yang kurang mampu (miskin). Hal ini sama dengan praktik yang dilaksanakan di MI al-Ihsan. Ukuran dan jenis ada perbedaan antara SDN Bandar II dan MI al-Ihsan, jenis dan ukuran zakat fitrah di SDN Bandar II adalah para siswa diwajibkan membayar zakat fitrah dengan bahan makanan pokok yaitu beras dengan jumlah $2,5 \mathrm{~kg}$ dengan menghimbau untuk melebihkan ukurannya, dan juga diperbolehkan membayar dengan uang dengan ketentuan jumlah uang yang dibayarkan ditentukan oleh pihak amil zakat di Sekolah dengan jumlah yang relative sesuai dengan harga beras yang standart tidak terlalu mahal dan tidak terlalu murah, kemudian uang tersebut dibelikan beras dengan kualitas yang standart. Sedangkan di MI al-Ihsan jenis zakat fitrah di wajibkan dengan menggunakan bahan makanan pokok yang dimakan oleh warga setempat yaitu beras dengan ketentuan $2,5 \mathrm{~kg}$ dengan tidak mewajibkan menggunakan jenis beras dengan kualitas terbaik. Namun meskipun demikian adapula yang membayar dengan menggunakan uang. Kemudian muzakki di SDN Bandar II adalah seluruh warga Sekolah, dan mustahiq adalah siswa yang kurang mampu(miskin), yatim piatu yang dianggap sebagai ibnu sabil dan juga warga sekitar Sekolah yang kurang mampu.

Kedua, SDN Bandar II melaksanakan praktik zakat fitrah berdasarkan perspektif mazhab Syafiei juga Hanafi. Sedangkan MI al-Ihsan, lebih pada kepraktisan dalam membayar zakat fitrah dengan membayarkan zakat fitrah di awal bulan Ramadhan, hal ini menurut mazhab Syafie $i$ maupun Hanafi juga diperbolehkan karena Hanafi memperbolehkan membayar zakat fitrah sejak awal tahun sehingga membayar zakat diluar bulan Ramadhan juga diperbolehkan. SDN Bandar II, MI al-Ihsan lebih cenderung kepada perspektif mazhab Syafie ${ }^{\circ}$, dimana yang dinyatakan miskin adalah adalah orang-orang yang mampu bekerja untuk menutupi kebutuhannya namun belum mencukupi, seperti orang yang membutuhkan sepuluh dia hanya mempunyai delapan sehingga tidak mencukupi sandang, pangan, papan. SDN Bandar II cenderung menggunakan pendapat mazhab Hanafi, dimana membolehkan membayar dengan menggunakan uang, selain itu jumlah uang yang ditentukan pihak amil zakat fitrah juga relatif, untuk mendapatkan beras dengan kualitas standart dan Karena pendapat Kepala MI al-Ihsan, membayar dengan uang tidak diperkenankan sudah sejak lama, mengingat bahwa MI al-Ihsan banyak menganut mazhab Syafie ${ }^{i}$.

\section{Daftar Pustaka}

Al-Quran Al Karim

Al-Syaikh, Yasin Ibrahim. Zakat membersihkan Kekayaan.

Al-Zuhayly, Wahbah. Zakat Kajian Berbagai Madzhab. Bandung: PT. Remaja Rosdakarya, 2005.

Hafidhuddin, Didin. Panduan Zakat. Jakarta: Republika, 2002.

Hasbi, Teuku Muhammad. Pedoman Zakat. Semarang: PT. Pustaka Rizki Putra, 1999.

Sabiq, Sayyid. Fiqih Sunnah. Jilid 3. Bandung: PT. Al Maeearif, 1985.

Jalaluddin Al-Mahalliy dan Imam Jalaluddin As-Suyuthi, Terjemah Tafsir Jalalain, Asbaabun

Nuzul

Jurisdictie: Jurnal Hukum dan Syariah Vol. 6 No. 2 Desember 2015 
az-Zuhaili, Wahbah. Fiqih Islam wa Adillatuhu Jilid 3, terj. Abdul Hayyin al-Kattani. Jakarta: Gema Insani, 2013

Isa al-Baqi al-Halabi, al-Muwaththa', (Kairo:Ihya al-Kutub al-Arabiyah 